\title{
Only reasoned action? An interorganizational study of energy-saving behaviors in office buildings
}

\author{
Siu Hing Lo • Gjalt-Jorn Y. Peters • Gerard J. P. van \\ Breukelen • Gerjo Kok
}

Received: 9 April 2013 / Accepted: 4 February 2014 /Published online: 22 February 2014

(C) The Author(s) 2014. This article is published with open access at Springerlink.com

\begin{abstract}
Substantial energy savings can be achieved by reducing energy use in office buildings. The reported study used a Theory of Planned Behavior (TPB) model extended with perceived habit to explain office energysaving behaviors. One aim was to examine if organizational contextual variability independently predicted office energy-saving behaviors over and above TPB variables and self-reported habit. Another aim was to examine the relative predictive value of TPB variables and habit for energy-saving behaviors between organizational contexts. Survey data on energy-saving behaviors, TPB variables, and habit and number of office mates were collected from office workers of four organizations in the Netherlands. The results indicate that intention was the strongest direct predictor of the behaviors printing smaller and not printing e-mails,
\end{abstract}

S. H. Lo $(\bowtie)$

Department of Epidemiology and Public Health, Health Behavior Research Centre, University College London, Gower Street, London WC1E 6BT, UK

e-mail: s.lo@ucl.ac.uk

\section{G.-. Y. Peters}

Open University of the Netherlands,

P.O. Box 2960, 6401 DL Heerlen, The Netherlands

G. J. P. van Breukelen

Department of Methodology and Statistics, Maastricht University,

P.O. Box 616, 6200 MD Maastricht, The Netherlands

G. Kok

Department of Work and Social Psychology, Maastricht University,

P.O. Box 616, 6200 MD Maastricht, The Netherlands whereas habit was the strongest predictor of the behaviors switching off lights and switching off monitors. Of the social-cognitive factors, attitude was the strongest predictor of intentions overall. The effect of perceived norm varied widely between behaviors and subgroups. Number of office mates had a direct, unmediated effect on the behavior switching off lights and a mediated effect via attitude and perceived control. The effect of organizational contextual variability on behavior was entirely mediated through the psychosocial factors for the two 'printing behaviors', but only partially for the two 'switching behaviors'. The relative predictive value of habit and intention differed between organizations. The findings suggest that organizational contextual variability has unconscious influences on some office energy-saving behaviors. Interventions should take variation in the relative importance of cognitive factors and habit between behaviors, and to a lesser extent between organizational contexts, into account.

Keywords Energy-saving in office buildings - Theory of Planned Behavior · Habit · Unconscious influences on behavior

\section{Introduction}

Accounting for almost one-fifth of non-domestic energy consumption, office buildings have the potential for substantial energy savings (de Groot and Morgenstern 2009; Perez-Lombard et al. 2008). In addition to improvements in technological efficiency and the use of 
renewable resources, factors influencing human behaviors need to be understood.

To date, little research has addressed energy use in organizations at the individual, behavioral level of analysis (Bansal and Gao 2006). More specifically, there is a lack of research examining the interaction between the organizational context and employee proenvironmental behaviors (Lo et al. 2012b). In other words, little is known about how organizational contextual variability affects employee energy-saving behaviors. Furthermore, the relatively scarce, existing organizational proenvironmental research on the individual level of analysis has focused on organizational members with job-specific environment-related responsibilities (Egmond et al. 2006; Vermeulen and Hovens 2006; Völlink et al. 2002). Although these key organizational members have a comparatively large impact on the organization's energy use, an understanding of other employees' views and behaviors is needed for energysaving investments and policies to be effective. Firstly, estimates suggest that considerable energy consumption reductions by means of behavioral measures only are feasible (Dietz et al. 2009). Secondly, people's behavior can (adversely) affect the effectiveness of technical measures implemented to save energy.

Previous research has shown that both cognitive and habitual factors influence energy-saving and other proenvironmental behaviors in household contexts (Bamberg et al. 2003; Bamberg and Moser 2007; Carrus et al. 2008; Knussen et al. 2004). However, one unexplored question is to what extent habitual influences are conscious and adequately captured by selfreport measures. Another question is the relative influence of psychosocial factors on behavior. The present study aimed to examine if organizational contextual variability independently predicts office energy-saving behaviors over and above the Theory of Planned Behavior (TPB) model and self-reported habit. A secondary aim was to explore variation in the relative importance of psychosocial factors between different energysaving behaviors.

\section{Conceptual framework}

\section{Planned behavior}

The Theory of Planned Behavior is an extensively researched social-cognitive model of behavior that has been comparatively successful at explaining energy- saving and other proenvironmental behaviors (Bamberg and Moser 2007; Kaiser et al. 2005). The TPB postulates that attitudes, perceived norms and perceived behavioral control determine behavioral intention - the most important immediate antecedent of behavior itself (Fishbein and Ajzen 2010).

'Attitudes' are an individual's overall evaluation of a behavior and comprises instrumental and experiential aspects (Fishbein and Ajzen 2010). Instrumental attitude is related to the outcome of a behavior and experiential attitude is linked to the experience of performing a behavior. For proenvironmental behavior, an individual's moral evaluation of a behavior, the 'personal norm' or 'moral norm', could also be relevant (Kaiser 2006; Parker et al. 1995). While some suggest a lack of discriminant validity between personal norm and attitude, others maintain it should be considered a distinct construct (Bamberg et al. 2007; Kaiser 2006).

'Perceived behavioral control' (PBC) refers to a person's evaluation of whether one has the necessary resources, knowledge, and/or skills to perform a behavior (Ajzen 1991). A distinction can be made between a capacity and an autonomy component of perceived behavioral control, the former referring to the ability to perform a behavior and the latter to the degree of control or discretion over performing a behavior (Fishbein and Ajzen 2010).

'Perceived norms' reflect influences of other people on the individual. A distinction can be made between injunctive norms, which concern others' approval/ disapproval of one's own behavior, and descriptive norms, which refer to others' behavior (Schultz et al. 2007). Most TPB research has used a forced-choice format, which does not allow for nonresponse, for measuring perceived norms and thereby assuming familiarity with the norm, but for proenvironmental behaviors especially, there is often an absence of perceived norm, i.e. not knowing what others think and do (Siero et al. 1984).

\section{Habit and unconscious influences}

When behaviors are repeatedly performed, they require increasingly less deliberative evaluation so that they eventually become habits (Fishbein and Ajzen 2010). Contextual cues like time and place tend to play a more salient role in determining habitual behavior than socialcognitive variables (Wood et al. 2005). 
Previous research assumed either that people were able to report habits (Knussen et al. 2004; Verplanken and Orbell 2003) or that self-reported past behavior was a good proxy of habit strength (Bamberg et al. 2003; Carrus et al. 2008). One issue is that such measures beg the question why people behave the way they do (Ajzen 2011). Another potential problem with perceived habit specifically is that it assumes people are (fully) conscious of their habits. A related question is whether self-reported influences fully explain behavior. Psychological research increasingly suggests that behavior is influenced by both conscious and unconscious factors (Aarts and Dijksterhuis 2000; Bargh and Morsella 2008; Hassin et al. 2009). Environmental cues, for example, are argued to influence behavior through conscious as well as unconscious processes (Kremers 2010).

For daily office energy-saving behaviors, the physical context (i.e., arrangement and availability of organizational facilities such as the location of light switches and the default printer settings) is the most obvious source of environmental cues and organizational contextual variability and has previously been shown to strongly influence employee office recycling behavior (Brothers et al. 1994; Humphrey et al. 1977). Qualitative findings suggest that employees believe that the arrangement and availability of facilities in the physical office environment heavily influence their energysaving behaviors (Lo et al. 2012a). However, employees seem to less easily identify other contextual influences. A telling example is one employee's attempt to explain why she left the lights on at work but not at home: “...I think it is a habit... because you always see lights burning everywhere...At my place it's dark except where I am... I think that's the reason why, I never really thought about it." Thus, although one can expect differences in the organizational environment to be at least partially reflected in its employees' beliefs about office energy-saving behaviors, it appears that some contextual features also have an unconscious influence on such behaviors. Another issue this raises is whether energysaving in offices is prone to "social loafing" due to the presence of (many) others and lack of financial incentives to save energy (Latane et al. 1979).

\section{Present study}

We tested to what extent a TPB model extended with perceived habit could explain office energy-saving behaviors. One specific aim was to examine if organizational contextual variability could explain variance over and above the extended TPB model. We hypothesized that:

(H1) Attitude, personal norm, perceived behavioral control, perceived norms, and perceived habit are together good predictors of intentions to save energy and energy-saving behaviors.

(H2a) The effect of organizational contextual variability on energy-saving behaviors will be partially mediated by the TPB constructs and habit.

(H2b) Organizational contextual variability will have a direct, unmediated effect on energy-saving behaviors, over and above the extended TPB model.

In addition, we addressed the explorative question whether the predictive value of TPB variables and habit for energy-saving behaviors differed between organizations and if so how.

\section{Methods}

Participants and procedure

Employees from four organizations in the Dutch provinces Zuid-Holland (ZH) and Limburg (LB) took part in an online survey study about energy consumption among office workers. Questions pertaining to office energy use were part of the larger survey. The sample of organizations consisted of two commercial companies (company $\mathrm{ZH}$; company LB), a university (university LB), and a non-governmental organization (NGO $\mathrm{ZH})$. We selected these organizations because of their diversity in organizational focus. Any similarities between these organizations are more likely to be generalizable to other organizations, whereas differences may indicate which parameters vary between organizations. Company ZH, university LB, company LB, and NGO $\mathrm{ZH}$ each participated with one to three office buildings, with a (combined) capacity of approximately 1,000, 700,450 , and 350 people, respectively. All organizations were publicly committed to environmental sustainability to a lesser or larger extent, but none had energy conservation as their primary organizational aim. Employees were approached by their own organization with the request to fill out the anonymous online survey. It was emphasized that the study was conducted by 
independent researchers and only the general anonymized results would be reported to the organization. Except for company LB employees, respondents could participate in a raffle contest for $€ 20$ gift vouchers.

\section{Measures}

Energy-saving behaviors and measures of psychosocial and other determinants were chosen based on an earlier qualitative study conducted at the same organizations (Lo et al. 2012a). Based on these findings, we selected a small number of behaviors for further investigation in the survey. Only behaviors that were comparable across office environments were selected. Energy-saving behaviors that some office workers had little control (e.g., climate control) and behaviors that a large majority of office workers reported to perform (e.g., switching off computers and lights at the end of the day) were also excluded. The qualitative findings were also used to select adjectives for the semantic differential scales for attitude measures, social referents for perceived norm measures, and beliefs to measure other psychosocial factors. Unless stated otherwise, all measures were rated on a five-point scale ranging from 1 to 5 , with 1 being the least proenvironmental and 5 the most proenvironmental.

\section{Office energy-saving behaviors}

The examined behaviors were 1. 'printing smaller' ("print more than one page on one A4 sheet"), 2. 'not printing e-mails' ("read e-mails without printing them out"), 3. 'switching off lights' (respondents with no office mates: "switch off the lights in my office when I am absent for a longer period of time during the day"/ respondents with office mates: "switch off the lights in my office when I and my office mates are absent for a longer period of time during the day"), and 4. 'switching off monitors' ("switch off my monitor when I go home"). Printing smaller and not printing e-mails will be referred to as 'printing behaviors', and switching off lights and monitors as 'switching behaviors'. Company $\mathrm{ZH}$ was excluded from interorganizational analyses of switching behaviors because it had motion-sensor lighting control in most parts of its office building and few employees had a monitor separate from their computer.

Behavior was measured with one item beginning with "The past month, I have... [e.g. switched off my monitor when I went home]", rated on a scale ranging from never to always. Because of our cross-sectional survey design, we used behavior of the past month as a proxy for current behavior. Although a limitation of the study design, previous research has shown that past behavior is generally a good proxy for future behavior in an unchanged environment (Bamberg et al. 2003; Ouellette and Wood 1998).

\section{Intention}

Behavioral intention was measured with two indicators, beginning with "Next month, I expect to... [e.g., switch off my monitor...]" (I1) and "Next month, I want to... [...]." (I2), rated on a scale ranging from never to always.

\section{Attitude}

Attitude towards each of the behaviors was measured on a semantic differential scale with a stem question [e.g., "Switching my monitor off ...is..."] and the adjective pairs "negative-positive" (IA1), "useless-useful" (IA2), "unpleasant-pleasant" (EA1), and "difficult-easy" (EA2). "Difficult-easy" is often used to measure the capacity component of PBC, but can correlate more highly with experiential attitude (Fishbein and Ajzen 2010) which was also the case in this study (e.g., $r=0.39$ vs. $r=0.65$ for printing smaller). We hypothesized that the former two pairs reflected instrumental aspects, whereas the latter would reflect experiential aspects. Instrumental and experiential attitude were modeled as first-order factors of an overarching second-order attitude factor.

\section{Personal norm}

We included a one-item morally evaluative measure, "I think employees of organization X ought to [e.g., switch off their monitor...]" (PN1), rated on a scale from disagree to agree. When speaking about the moral dimension of behaviors, qualitative findings suggested it was more natural for employees to refer to all employees than they themselves personally. As the personal normitem refers to one's evaluation of other people, it was kept as a separate factor. 


\section{Perceived control}

The autonomy-component of $\mathrm{PBC}$, termed 'perceived control' here, was measured with the item "If I want to, I think I can manage to [e.g., switch off my monitor...]" (C1), rated on a scale ranging from disagree to agree.

\section{Perceived norms}

Injunctive and descriptive norm were modeled as firstorder factors of a second-order perceived norm factor. The injunctive norm measure consisted of three items stating "My superior(s) (ISN1)/colleagues (ISN2)/people in my private life who are important to me (ISN3) think I should [e.g., switch off my monitor...]", rated on a scale ranging from disagree to agree, with an additional option I really do not know. The descriptive norm items included two items stating "My superiors (DSN1)/ colleagues (DSN2) [e.g., switch off their monitor...... ]", rated on a scale ranging from never to always and the option I really do not know. The answer category I really do not know was recoded into the scale center (neutral for injunctive norm and sometimes for descriptive norm) for the total sample analyses, while allowing for a subgroup analysis of those respondents who were familiar with the relevant norm. This made examination of attenuation effects due to absence of perceived norm possible. The operational definition of this subgroup was ability to gauge the injunctive norm of one's superiors.

\section{Habit}

Habit was measured with two items selected from Verplanken's index of habit strength, namely "I [e.g., switch off my monitor...] without consciously thinking about it" (H1) and "I routinely [...]" (H2), rated on a scale ranging from disagree to agree (Verplanken and Orbell 2003).

\section{Organizational contextual variables}

Two items were used to measure organizational contextual variability: organization (i.e., the organization to which each respondent belonged) and the number of office mates of each respondent (continuous variable).
Data analysis

The extended TPB model of office energy-saving behaviors was tested using confirmatory factor analysis (CFA) and structural equation modeling (SEM) with Mplus version 6 (Muthén \& Muthén 1998-2010). All four energy-saving behaviors had a few to most items violating the normality assumption (i.e., skewness and/ or kurtosis values $>1$ ). As non-normality of indicators can lead to inflated ML $\chi^{2}$ goodness-of-fit statistics and underestimated standard errors, the models were estimated with robust maximum likelihood (Satorra and Bentler 1994). Unless stated otherwise, $\mathrm{Hu}$ and Bentler's recommendations for evaluating goodness of fit were followed, with around .95 and above for CFI and TLI, and around .08 and below for RMSEA and SRMR as indicators of good fit (Hu and Bentler 1999).

We first tested the measurement models on the total sample with CFA to confirm the relationship between the latent factors (i.e., the psychosocial factors and intention) and their observed indicators (i.e., the measurement items). We specified indicators of psychosocial factors and intention to only load on their own factor. Measurement errors were assumed to be uncorrelated, while all factors were allowed to correlate with each other. We then tested a baseline model that specified the hypothesized relationships between the psychosocial factors, intention and behavior with SEM (H1). We hypothesized that (1) the latent factors attitude, personal norm, social norm, and perceived control all affected intention; (2) the latent factor habit affected both intention and behavior; and (3) intention affected behavior. Except for intention and behavior, all other latent factors were allowed to correlate freely because there were no hypotheses concerning the relationships between these factors.

The effect of number of office mates on energysaving behaviors was tested by adding the variable as a predictor of all latent factors in the baseline SEM model $(\mathrm{H} 2 \mathrm{a}-\mathrm{b})$. Insignificant paths were removed from the model before interpreting the effect. The effect of the categorical variable organization on energy-saving behaviors was tested using ANCOVA with organization as a between-subject factor and the psychosocial measures (and number of office mates if a significant predictor) as covariates $(\mathrm{H} 2 \mathrm{a}-\mathrm{b})$.

Multigroup SEM analyses were used to test for organizational differences in the relative importance of psychosocial factors in the extended TPB model. We 
compared models using Satorra-Bentler scaled chisquare difference tests, following the Mplus User's Guide guidelines (Muthén \& Muthén 1998-2010; Satorra and Bentler 2001). Configural invariance, which is an omnibus test for whether the same path model fits each group/organization, was first tested. Following this, equality constraints on path coefficients between latent factors were imposed to test for group differences in the structural model. A rejection of structural equality implies that some path coefficients between psychosocial factors and intention and behavior differ between organizations. Partial invariance tests were then conducted to check which part(s) of the structural model were different. If structural invariance was rejected for a path coefficient, results from the configural model were used to calculate the ratio between the lowest and the highest standardized factor path coefficients between organizations.

\section{Results}

Sample characteristics

Over half (54\%) of the respondents were female (NGO ZH, $62 \%$; Company ZH, 41 \%; University LB, $69 \%$; and Company LB, $44 \%$ ). The average age was 42 years (NGO ZH, 43; Company ZH, 42; University LB, 40; and Company LB, 46). A large majority (79\%) had received higher education (NGO ZH, $81 \%$; Company ZH, $78 \%$; University LB, $82 \%$; and Company LB, $75 \%$ ). Roughly one-fifth (22\%) of respondents did not share an office with others with large variations across organizations (NGO ZH, $5 \%$; Company ZH, $18 \%$; University LB, $21 \%$; and Company LB, $56 \%$ ). Of those who had started the questionnaire, the completion rates for company $\mathrm{ZH}$, company $\mathrm{LB}$, university $\mathrm{LB}$, and NGO ZH were 55, 65, 69, and $84 \%$, respectively. Response rates were not calculated because the number of employees reached by the invitation could not be reliably established.

The extended Theory of Planned Behavior model

On average, respondents indicated they performed the four examined office energy-saving behaviors sometimes to often. Means, standard deviations of each investigated office energy-saving behavior are presented by organization in Table 1 . The measurement models had an acceptable fit for all behaviors (see model 1 in Table 2). We then tested the structural model on the total sample (see model 2 in Table 2) and on the group of respondents familiar with social norms. For the total sample, correlation matrices of all latent constructs of printing and switching behaviors are provided in Tables 3 and 4, respectively. For printing behaviors, a model with a second-order attitude factor showed a good fit. For switching behaviors, a model with a second-order attitude factor gave negative residual variances in some organizations. We therefore collapsed the instrumental and experiential attitude factor into a single attitude factor, which provided admissible solutions for these behaviors. In addition, for switching off lights, we allowed for correlated errors between the injunctive and descriptive norm items of the same social referents for the same reason. Figures 1, 2, 3, and 4 show the standardized factor loadings and path coefficients of the baseline models for printing smaller, not printing emails, switching off lights, and switching off monitors, respectively. The explained variance of intention and behavior was between 0.50 and 0.74 for printing smaller $\left(R_{\text {intention }}^{2}=0.69 / R_{\text {behavior }}^{2}=0.63\right)$, not printing e-mails $\left(R_{\text {intention }}^{2}=0.50 / R_{\text {behavior }}^{2}=0.53\right)$, switching off lights $\left(R_{\text {intention }}^{2}=0.67 / R_{\text {behavior }}^{2}=0.56\right)$, and switching off monitors $\left(R_{\text {intention }}^{2}=0.60 / R_{\text {behavior }}^{2}=0.74\right)$.

Most hypothesized effects were significant at the .05 level and the hypothesized model showed a good overall fit. Intention was the strongest direct predictor of printing behaviors, while habit was the strongest predictor of switching behaviors. Attitude had the strongest effect on intention for all behaviors. Habit was also a significant direct predictor of intention for all behaviors. The effects of perceived norm, personal norm, and perceived control were less consistent across behaviors. Perceived norm was a significant predictor of printing intentions and intention to switch off monitors, but not intention to switch off lights. Personal norm was a significant predictor of printing intentions, but not of switching intentions. Perceived control significantly predicted printing intentions and intention to switch of lights, but not intention to switch off monitors.

Compared to the total sample, standardized regression coefficients for the subgroup familiar with social norms tended to differ only slightly as shown in Figs. 1, 2, 3, and 4. However, there were a few substantial exceptions. For not printing e-mails, the effect of perceived norm on intention was higher than in the total sample and was larger 
Table 1 Energy-saving behaviors: means and SDs by organization

\begin{tabular}{|c|c|c|c|c|c|c|c|c|}
\hline & Total & NGO ZH & Company ZH & University LB & Company LB & $\mathrm{F}$ & $p$ value & $\eta^{2}$ \\
\hline Print smaller & 3.24 & 3.13 & 3.45 & 3.04 & 3.34 & 5.95 & $<.001$ & .018 \\
\hline SD & 1.26 & 1.38 & 1.16 & 1.28 & 1.19 & 1.08 & $n s$ & \\
\hline$N$ & 970 & 245 & 290 & 275 & 160 & & & \\
\hline Not print e-mails & 3.98 & 3.87 & 4.00 & 4.12 & 3.89 & 7.43 & $<.001$ & .023 \\
\hline SD & 0.67 & 0.69 & 0.68 & 0.65 & 0.61 & 0.36 & $n s$ & \\
\hline$N$ & 970 & 245 & 290 & 275 & 160 & & & \\
\hline Switch off monitor & 4.09 & 3.85 & 4.26 & 4.08 & 4.41 & 5.39 & $<.001$ & .023 \\
\hline $\mathrm{SD}$ & 1.44 & 1.58 & 1.30 & 1.41 & 1.21 & 3.96 & $<.01$ & .018 \\
\hline$N$ & 687 & 249 & 68 & 209 & 161 & & & \\
\hline Switch off lights & 3.63 & 3.04 & N/A & 3.86 & 4.14 & 41.54 & $<.001$ & .117 \\
\hline SD & 1.34 & 1.40 & & 1.20 & 1.11 & 16.41 & $<.001$ & .052 \\
\hline$N$ & 631 & 231 & & 251 & 149 & & & \\
\hline
\end{tabular}

$F$ and $p$ values in italics: corrected for differences in psychosocial measures using ANCOVA

than the effect of attitude (see Fig. 2). Furthermore, personal norm and habit did not have a significant effect on intention not to print e-mails in this subgroup. For printing smaller, there was an increase in the perceived and personal norm coefficients and a decrease in the attitude coefficient. As a result, contrary to the total sample, personal norm had a significant effect in this

Table 2 Office energy-saving behaviors: goodness of fit statistics

\begin{tabular}{|c|c|c|c|c|c|c|c|c|c|c|c|}
\hline Model & $\chi^{2}$ & $\mathrm{SB} \chi^{2}$ & $\mathrm{df}$ & $\Delta \chi^{2}$ & $\Delta \mathrm{df}$ & $\Delta \mathrm{p}$ & CFI & TLI & RMSEA & SRMR & $\begin{array}{l}\text { Scaling } \\
\text { correct factor }\end{array}$ \\
\hline \multicolumn{12}{|l|}{ Printing smaller } \\
\hline 1. CFA total sample & & 239.849 & 73 & & & & 0.975 & 0.964 & 0.051 & 0.032 & \\
\hline 2. SEM total sample & & 266.808 & 86 & & & & 0.975 & 0.966 & 0.048 & 0.033 & \\
\hline 3. Multigroup, configural & 606.235 & 527.684 & 344 & & & & 0.977 & 0.967 & 0.049 & 0.043 & 1.149 \\
\hline 4. Multigroup, equal structural & 629.997 & 548.438 & 365 & 20.681 & 21 & $>.10$ & 0.977 & 0.969 & 0.047 & 0.047 & 1.149 \\
\hline \multicolumn{12}{|l|}{ Not printing e-mails } \\
\hline 1. CFA total sample & & 145.633 & 73 & & & & 0.987 & 0.981 & 0.033 & 0.024 & \\
\hline 2. SEM total sample & & 186.182 & 86 & & & & 0.984 & 0.977 & 0.036 & 0.026 & \\
\hline 3. Multigroup, configural & 517.292 & 465.911 & 344 & & & & 0.981 & 0.973 & 0.040 & 0.040 & 1.11 \\
\hline 4. Multigroup, equal structural & 582.087 & 514.859 & 365 & 43.929 & 21 & $<.01$ & 0.976 & 0.969 & 0.043 & 0.044 & 1.131 \\
\hline \multicolumn{12}{|l|}{ Switching off lights } \\
\hline 1. CFA total sample & & 230.829 & 73 & & & & 0.965 & 0.950 & 0.059 & 0.044 & \\
\hline 2. SEM total sample & & 225.210 & 86 & & & & 0.972 & 0.961 & 0.051 & 0.041 & \\
\hline 3. Multigroup, configural & 510.148 & 443.181 & 258 & & & & 0.965 & 0.951 & 0.059 & 0.049 & 1.151 \\
\hline 4. Multigroup, equal structural & 546.705 & 469.798 & 272 & 26.046 & 14 & $<.05$ & 0.963 & 0.951 & 0.060 & 0.056 & 1.164 \\
\hline \multicolumn{12}{|l|}{ Switching off monitor } \\
\hline 1. Measurement model & & 195.381 & 73 & & & & 0.965 & 0.950 & 0.053 & 0.042 & \\
\hline 2. Baseline model & & 221.029 & 88 & & & & 0.967 & 0.955 & 0.050 & 0.041 & \\
\hline 3. Multigroup, configural & 527.449 & 413.645 & 264 & & & & 0.965 & 0.953 & 0.053 & 0.053 & 1.275 \\
\hline 4. Multigroup, equal structural & 574.328 & 438.575 & 278 & 23.796 & 14 & $<.05$ & 0.963 & 0.952 & 0.054 & 0.056 & 1.31 \\
\hline
\end{tabular}

${ }^{\text {a }}$ Scaling method: loading of first indicator of each factor constrained to 1 
Table 3 Printing behaviors: correlations between latent constructs

\begin{tabular}{lllllllllllll}
\hline & Behavior & Intention & Attitude & $\begin{array}{l}\text { Att. } \\
\text { instrum. }\end{array}$ & $\begin{array}{l}\text { Att. } \\
\text { experien. }\end{array}$ & $\begin{array}{l}\text { Perceived } \\
\text { norm }\end{array}$ & $\begin{array}{l}\text { Inj. } \\
\text { norm }\end{array}$ & $\begin{array}{l}\text { Descr. } \\
\text { norm }\end{array}$ & $\begin{array}{l}\text { Personal } \\
\text { norm }\end{array}$ & $\begin{array}{l}\text { Perceived } \\
\text { control }\end{array}$ \\
\hline Behavior & 1.00 & 0.77 & 0.62 & 0.53 & 0.58 & 0.51 & 0.35 & 0.39 & 0.47 & 0.35 & 0.53 \\
Intention & 0.73 & 1.00 & 0.79 & 0.67 & 0.75 & 0.63 & 0.43 & 0.49 & 0.62 & 0.45 & 0.50 \\
Attitude & 0.46 & 0.62 & 1.00 & 0.85 & 0.94 & 0.60 & 0.41 & 0.47 & 0.70 & 0.46 & 0.43 \\
Att. instrum. & 0.39 & 0.53 & 0.86 & 1.00 & 0.80 & 0.51 & 0.35 & 0.40 & 0.60 & 0.39 & 0.36 \\
Att. experien. & 0.41 & 0.55 & 0.88 & 0.76 & 1.00 & 0.57 & 0.39 & 0.44 & 0.66 & 0.44 & 0.40 \\
Perceived norm & 0.40 & 0.54 & 0.54 & 0.47 & 0.48 & 1.00 & 0.69 & 0.78 & 0.56 & 0.35 & 0.42 \\
Inj. norm & 0.21 & 0.29 & 0.29 & 0.25 & 0.25 & 0.53 & 1.00 & 0.53 & 0.38 & 0.24 & 0.29 \\
Descr. norm & 0.29 & 0.40 & 0.40 & 0.34 & 0.35 & 0.74 & 0.39 & 1.00 & 0.43 & 0.27 & 0.33 \\
Personal norm & 0.41 & 0.57 & 0.62 & 0.53 & 0.54 & 0.59 & 0.31 & 0.44 & 1.00 & 0.46 & 0.29 \\
Perceived control & 0.34 & 0.46 & 0.48 & 0.41 & 0.42 & 0.38 & 0.20 & 0.28 & 0.49 & 1.00 & 0.22 \\
Habit & 0.33 & 0.37 & 0.37 & 0.32 & 0.33 & 0.26 & 0.14 & 0.19 & 0.21 & 0.25 & 1.00 \\
\hline
\end{tabular}

Correlations latent constructs printing smaller: above diagonal; correlations latent constructs not printing e-mails: below diagonal

subgroup. For switching off lights, the effect personal norm on intention was not significant in this subgroup.

\section{Number of office mates}

Number of office mates had a direct, unmediated negative effect on the behavior switching off lights (standardized $b=-.101, p<.001$ ), but not on the other three behaviors. There were also indirect, mediated effects: number of office mates also had negative effects on attitude towards (standardized $b=-.214, p<.05$ ) and perceived control over (standardized $b=-.138, p<.05$ ) switching off lights. Including number of office mates did not alter the significance and direction of regression weights of the paths from psychosocial factors to intention and behavior. We therefore excluded number of office mates from further analyses to facilitate comparison between behaviors.

\section{Organization}

There were significant organizational differences in the four behaviors (see Table 1), although the effect sizes of organization on behavior were small (i.e., $\eta^{2} \leq .023$ ), except for a close to large effect size for switching off lights $\left(\eta^{2}=0.117\right)$. For both printing behaviors, the effect of organization was non-significant after including

Table 4 Switching behaviors: correlations between latent constructs

\begin{tabular}{llllllllll}
\hline & Behavior & Intention & Attitude & Perceived norm & Inj. norm & Descr. norm & Personal norm & Perceived control & Habit \\
\hline Behavior & 1.00 & 0.66 & 0.49 & 0.40 & 0.25 & 0.36 & 0.45 & 0.37 & 0.71 \\
Intention & 0.66 & 1.00 & 0.72 & 0.44 & 0.28 & 0.40 & 0.64 & 0.51 & 0.67 \\
Attitude & 0.53 & 0.70 & 1.00 & 0.36 & 0.23 & 0.32 & 0.68 & 0.46 & 0.32 \\
Perceived norm & 0.51 & 0.51 & 0.39 & 1.00 & 0.64 & 0.90 & 0.40 & 0.51 \\
Inj. norm & 0.31 & 0.32 & 0.24 & 0.62 & 1.00 & 0.57 & 0.26 & 0.21 & 0.29 \\
Descr. norm & 0.43 & 0.44 & 0.34 & 0.86 & 0.53 & 1.00 & 0.36 & 0.33 \\
Personal norm & 0.43 & 0.54 & 0.68 & 0.36 & 0.22 & 0.31 & 1.00 & 0.48 & 0.47 \\
Perceived control & 0.16 & 0.21 & 0.24 & 0.03 & 0.02 & 0.03 & 0.16 & 0.48 \\
Habit & 0.84 & 0.62 & 0.53 & 0.56 & 0.34 & 0.48 & 0.44 & 0.16 & 0.42 \\
\hline
\end{tabular}

Correlations latent constructs switching off lights: above diagonal; correlations latent constructs switching off monitor: below diagonal 


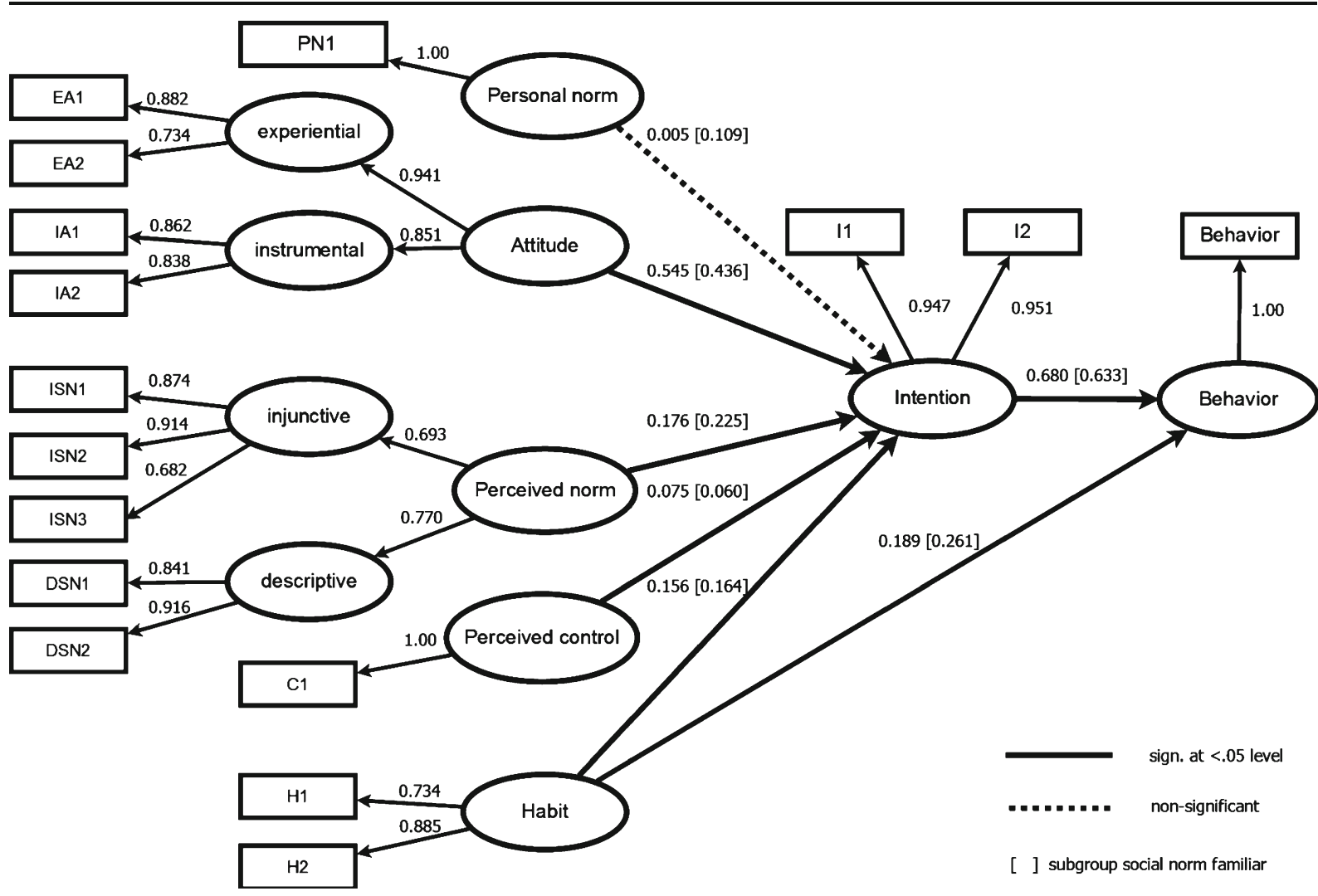

Fig. 1 Structural equation model printing smaller (standardized loadings and path coefficients)

indicators of psychosocial variables as covariates. However, for switching behaviors, psychosocial variables (and number of office mates for switching off lights) only partially explained the interorganizational differences. Organizational differences in switching off lights were reduced to a medium effect size $\left(\eta^{2}=.052\right)$ and in switching off monitors to a small effect size $\left(\eta^{2}=.018\right)$ after covariate adjustment.

Organizational differences in the relative influence of psychosocial factors

Configural invariance of the baseline models was first tested, with the results showing acceptable goodness-offit indices (see model 3 in Table 2). Compared to the configural invariance model, structural invariance only held for printing smaller, but not for not printing e-mails and the switching behaviors (printing smaller: $\Delta \mathrm{SB} \chi^{2}=$ 20.68, df $=21$, ns; not printing e-mails: $\Delta \mathrm{SB} \chi^{2}=43.93$, $\mathrm{df}=21, p<.01$; lights: $\Delta \mathrm{SB} \chi^{2}=26.05, \mathrm{df}=14, p<.05$; and monitor: $\Delta \mathrm{SB} \chi^{2}=23.80, \mathrm{df}=14, p<.05$ ). Thus, for most behaviors, there are some differences in the magnitude of relationships between psychosocial factors, intention, and behavior across organizations.

For the switching behaviors and not printing e-mails, partial invariance tests were used to examine for which parts of the model structural invariance was rejected (see Table 5). There were only significant violations found for paths between habit, intention, and behavior. For not printing e-mails, the path between habit and behavior differed significantly between organizations $\left(\Delta \mathrm{SB} \chi^{2}=\right.$ $14.55, \mathrm{df}=3, p<.01$, ratio $=.04)$. Unlike the other organizations, company LB showed a significant path between habit and behavior (standardized $b=.40$ ). Also the path between intention and behavior differed for not printing e-mails $\left(\Delta \mathrm{SB} \chi^{2}=25.55, \mathrm{df}=3, p<.001\right.$, ratio=.77). For company $\mathrm{ZH}$, the effect of intention on behavior (standardized $b=.82$ ) was slightly higher than for other organizations. For switching off lights, the effect of habit on intention differed between organizations $\left(\Delta \mathrm{SB} \chi^{2}=7.91, \mathrm{df}=2, p<.05\right.$, ratio=.32). Company LB did not have a significant coefficient for habit on intention, unlike the other organizations. For switching off monitors, the effect of habit on behavior differed 




Fig. 2 Structural equation model not printing e-mails (standardized loadings and path coefficients)

$\left(\Delta \mathrm{SB} \chi^{2}=10.31, \mathrm{df}=2, p<.01\right.$, ratio=0.73). Company LB's coefficient for habit on behavior (standardized $b=.54$ ) was slightly lower than in other organizations.

\section{Discussion}

This study tested an extended TPB model of office energy-saving behaviors. Similar to previous studies on proenvironmental behaviors in private households, the extended TPB model proved to fit the data well (e.g., Harland et al. 1999; Kaiser et al. 2005; Thogersen 2006). However, it did not always provide a complete account of all investigated energy-saving behaviors.

Intention was a stronger direct predictor of printing behaviors than (perceived) habit, but the reverse was true for switching behaviors. Social-cognitive factors and habit were mostly significant predictors of intention. Attitude was the strongest predictor of intention for all behaviors in total sample analyses, but in the group familiar with the relevant norm, perceived norm was a stronger predictor of intention not to print e-mails. This suggests that attitude is not always the strongest predictor of intention for office energy-saving behaviors. When relevant social norms are salient, perceived norms might play a more prominent role than the total sample results suggest. This is consistent with previous qualitative findings that suggest limited awareness of social norms related to energy saving (Lo et al. 2012a; Siero et al. 1984). However, the effect of perceived norm is less consistent than that of attitude; the effect of perceived norm on intention to switch off lights when no one is in the room was non-significant, even among those familiar with the norm.

As discussed earlier, we did not incorporate $\mathrm{PBC}$ as a fully independent predictor because the capacity component of PBC - measuring perceived difficulty of the behavior - was incorporated in the model as an experiential attitude item. This finding is also in line with previous qualitative findings that suggest the use of the word "control" is often ambiguous and can refer to PBC as well as attitude and personal norm considerations (Lo et al. 2012a). The one-item perceived control factor that reflected the autonomy component of PBC had inconsistent effects on energy-saving intentions. This implies that perceived autonomy does not heavily influence 


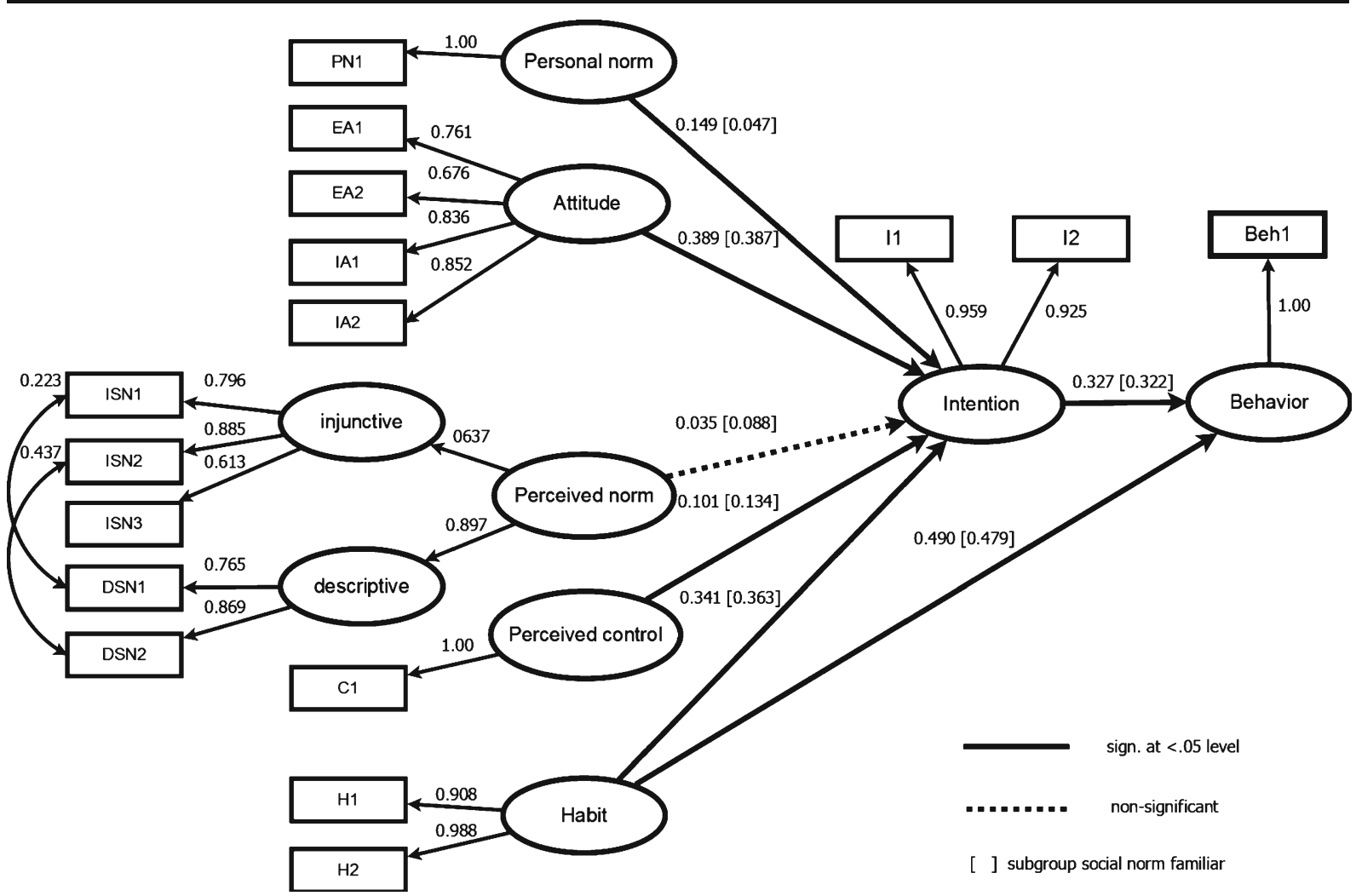

Fig. 3 Structural equation model switching off lights (standardized loadings and path coefficients)

simple, daily energy-saving behaviors. Another construct that can overlap with attitude is personal norm, which was kept as a separate factor. Personal norm only had a significant effect on intention for two out of four behaviors. This could indicate that moral evaluation has an inconsistent effect on energy-saving behaviors over and above attitude, although the one-item measure for personal norm in our study might have been unreliable. Considering the limitations of the PBC and personal norm measures in the present study, a more detailed investigation of their role in energy-saving behaviors in future would be useful.

Number of office mates had an unmediated, negative effect on the behavior switching off lights when no one is in the room, over and above the extended TPB model. No effect was found for switching off the monitor and the printing behaviors. Number of office mates also had a negative effect on attitude towards and perceived control over switching off lights. This suggests that the number of office mates has both unconscious and conscious influences on switching off lights. Consistent with a social loafing hypothesis, the larger the number of people sharing, the less inclined one is to switch lights off when no one is present. Office mates were more relevant to switching off lights than other examined behaviors because it was the only behavior we examined for which employees shared responsibility. Future research should examine whether other contextual factors also have unconscious influences on energysaving behavior besides their conscious influences on psychosocial factors.

After controlling for psychosocial factors, organizational differences in the average reported behaviors disappeared for printing behaviors, but remained significant for switching behaviors, although differences were reduced. In other words, the extended TPB model did not fully account for organizational differences in switching behaviors. A notable difference between behaviors in the SEM model results was the relative effect of habit on behavior, with stronger effects of habit for switching behaviors compared with printing behaviors.

There were also a few organizational differences in the predictive value (i.e., path coefficients) between 


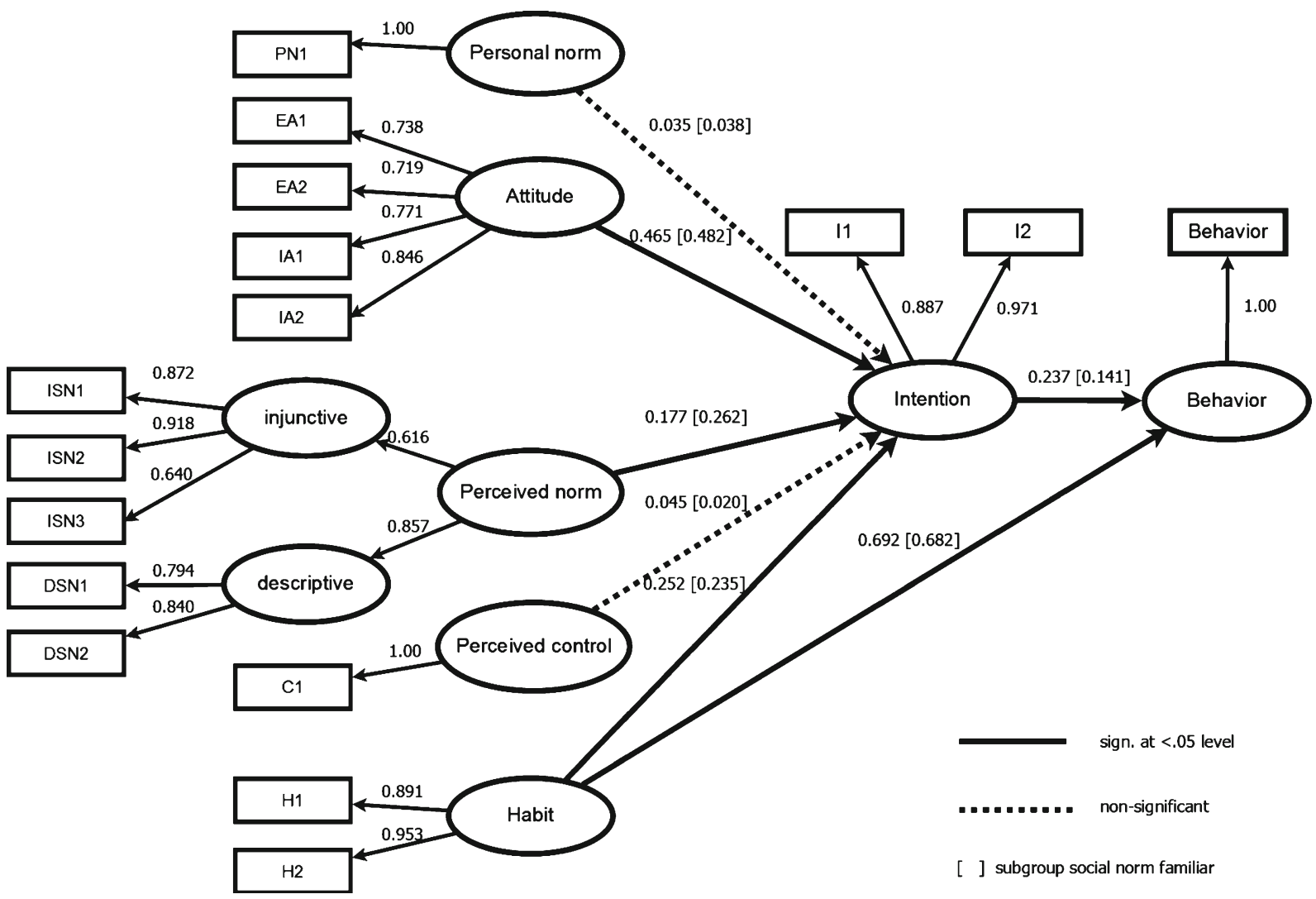

Fig. 4 Structural equation model switching off monitor (standardized loadings and path coefficients)

habit, intention, and behavior, but none between socialcognitive factors and intention. Previous qualitative evidence also found variation in the degree of habituation between individuals and departments (cf. Lo et al. 2012a). Therefore, the relative effect of habit and intention on energy-saving behaviors should first be established before implementing interventions at specific sites. Equally, it is reassuring that the influence of social-cognitive factors on intention appears to be stable between contexts.

Finally, the results of our study should be interpreted in the light of several general limitations. Participation in the online survey was voluntary. Given the varying completion rates, some differences could be due to selective participation of employees in the organizations. Having said that, the study's focus was on exploring if and how organizational context could influence individual office energy-saving behavior rather than making claims about the specific organizations examined. Future research should further examine why organizational differences affect office energy- saving behaviors. The reliance on self-reported cross-sectional data was another constraint, so no claims regarding the direction of causality can be made. Longitudinal and/or experimental research designs may overcome these shortcomings in future.

Implications for interventions

The TPB approach to behavior change is a planned process in three phases: elicitation of the relevant beliefs, changing intentions by changing salient beliefs and their respective social-cognitive determinants, and finally, changing behavior by changing intentions and increasing skills or decreasing environmental constraints (Fishbein and Ajzen 2010).

It is therefore important to first identify salient beliefs. In the context of this study, qualitative research was conducted for this purpose (Lo et al. 2012a). The comparative quantitative research described in this paper then examined differences in the relative influence of social- 
Table 5 Partial invariance of the structural model: not printing e-mails and switching behaviors

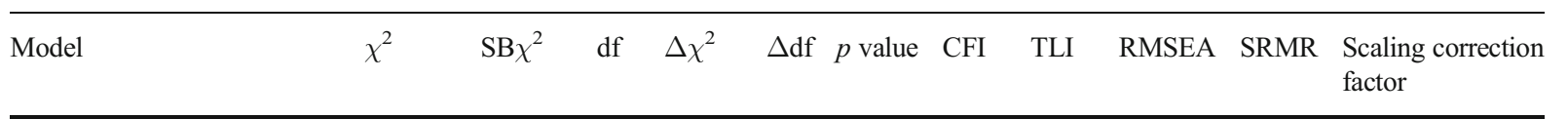

\begin{tabular}{|c|c|c|c|c|c|c|c|c|c|c|c|}
\hline \multicolumn{12}{|l|}{ Not printing e-mails } \\
\hline \# Multigroup. configural & 517.292 & 465.911 & 344 & & & & 0.981 & 0.973 & 0.040 & 0.040 & 1.110 \\
\hline a. Invariance $\mathrm{FA} \rightarrow \mathrm{FI}$ & 522.163 & 469.035 & 347 & 3.343 & 3 & $>.10$ & 0.981 & 0.973 & 0.040 & 0.041 & 1.113 \\
\hline b. Invariance FSN $\rightarrow$ FI & 518.618 & 467.202 & 347 & 1.195 & 3 & $>.10$ & 0.981 & 0.974 & 0.039 & 0.040 & 1.110 \\
\hline c. Invariance FPC $\rightarrow$ FI & 518.055 & 466.256 & 347 & 0.623 & 3 & $>.10$ & 0.981 & 0.974 & 0.039 & 0.040 & 1.111 \\
\hline d. Invariance FPN $\rightarrow$ FI & 526.679 & 473.464 & 347 & 6.998 & 3 & $>.05$ & 0.980 & 0.972 & 0.040 & 0.040 & 1.112 \\
\hline e. Invariance $\mathrm{FH} \rightarrow \mathrm{FI}$ & 519.667 & 468.194 & 347 & 2.140 & 3 & $>.10$ & 0.981 & 0.973 & 0.040 & 0.040 & 1.110 \\
\hline f. Invariance $\mathrm{FH} \rightarrow \mathrm{FB}$ & 545.22 & 488.283 & 347 & 14.548 & 3 & $<.01$ & 0.978 & 0.969 & 0.043 & 0.042 & 1.117 \\
\hline g. Invariance FI $\rightarrow$ FB & 584.065 & 481.666 & 347 & 25.548 & 3 & $<.001$ & 0.979 & 0.971 & 0.042 & 0.042 & 1.123 \\
\hline \multicolumn{12}{|l|}{ Switching off lights } \\
\hline \# Multigroup. configural & 510.148 & 443.181 & 258 & & & & 0.965 & 0.951 & 0.059 & 0.049 & 1.151 \\
\hline a. Invariance FA $\rightarrow$ FI & 511.102 & 442.244 & 260 & 0.530 & 2 & $>.10$ & 0.966 & 0.952 & 0.059 & 0.049 & 1.156 \\
\hline b. Invariance FSN $\rightarrow$ FI & 512.167 & 446.001 & 260 & 2.653 & 2 & $>.10$ & 0.965 & 0.951 & 0.059 & 0.050 & 1.148 \\
\hline c. Invariance FPC $\rightarrow$ FI & 513.684 & 444.859 & 260 & 2.116 & 2 & $>.10$ & 0.965 & 0.952 & 0.059 & 0.049 & 1.155 \\
\hline d. Invariance FPN $\rightarrow$ FI & 512.402 & 443.841 & 260 & 1.463 & 2 & $>.10$ & 0.965 & 0.952 & 0.059 & 0.049 & 1.154 \\
\hline e. Invariance $\mathrm{FH} \rightarrow \mathrm{FI}$ & 521.315 & 452.137 & 260 & 7.914 & 2 & $<.05$ & 0.964 & 0.950 & 0.060 & 0.050 & 1.153 \\
\hline f. Invariance $\mathrm{FH} \rightarrow \mathrm{FB}$ & 519.228 & 449.495 & 260 & 5.434 & 2 & $>.05$ & 0.964 & 0.950 & 0.060 & 0.050 & 1.155 \\
\hline g. Invariance FI $\rightarrow$ FB & 514.603 & 445.518 & 260 & 2.666 & 2 & $>.10$ & 0.965 & 0.952 & 0.059 & 0.049 & 1.155 \\
\hline \multicolumn{12}{|l|}{ Switching off monitor } \\
\hline \# Multigroup. configural & 527.449 & 413.645 & 264 & & & & 0.965 & 0.953 & 0.053 & 0.053 & 1.275 \\
\hline a. Invariance FA $\rightarrow$ FI & 535.795 & 417.256 & 266 & 3.376 & 2 & $>.10$ & 0.965 & 0.953 & 0.053 & 0.054 & 1.284 \\
\hline b. Invariance FSN $\rightarrow$ FI & 528.61 & 415.388 & 266 & 1.151 & 2 & $>.10$ & 0.965 & 0.953 & 0.053 & 0.053 & 1.273 \\
\hline c. Invariance FPC $\rightarrow$ FI & 533.597 & 417.957 & 266 & 3.990 & 2 & $>.10$ & 0.965 & 0.952 & 0.054 & 0.053 & 1.277 \\
\hline d. Invariance FPN $\rightarrow$ FI & 535.333 & 418.99 & 266 & 4.710 & 2 & $>.05$ & 0.965 & 0.952 & 0.054 & 0.053 & 1.278 \\
\hline e. Invariance $\mathrm{FH} \rightarrow \mathrm{FI}$ & 531.883 & 417.179 & 266 & 3.478 & 2 & $>.10$ & 0.965 & 0.953 & 0.053 & 0.054 & 1.275 \\
\hline f. Invariance $\mathrm{FH} \rightarrow \mathrm{FB}$ & 552.932 & 430.617 & 266 & 10.309 & 2 & $<.01$ & 0.962 & 0.949 & 0.056 & 0.054 & 1.284 \\
\hline g. Invariance $\mathrm{FI} \rightarrow \mathrm{FB}$ & 534.554 & 415.727 & 266 & 2.595 & 2 & $>.10$ & 0.965 & 0.953 & 0.053 & 0.054 & 1.286 \\
\hline
\end{tabular}

FA attitude, FAE experiential attitude, FAI instrumental attitude, FPC perceived control, FPN personal norm, FSN perceived norm, FSI injunctive norm, $F S D$ descriptive norm, $F H$ habit, $F I$ intention, $F B$ behavior

cognitive determinants and habit. The presented findings have several implications for behavior change interventions. Before implementing interventions at specific organizational sites, the relative influence of habit and intention on office energy-saving behaviors should always first be established because these are the most variable between contexts. In contrast, social-cognitive influences are likely to be more generalizable between contexts which allows for more standardization of interventions in this respect.

Fishbein and Ajzen recognize methods such as persuasive communication, use of arguments, framing, active participation, modeling, and group discussion (Fishbein and Ajzen 2010). However, these methods will only be effective if salient behavioral, normative, or control beliefs are changed. The successful extension of the TPB model in the present study further suggests that change methods appropriate for habitual behavior may also be needed. Examples of such methods include implementation intentions, cue altering, counter conditioning, stimulus control, and public commitment (Bartholomew et al. 2011). The most appropriate method or range of methods should be selected based on the results of each relevant behavior and context-specific findings. In the present study, the results suggest that methods aimed 
at changing social-cognitive beliefs are likely to be more effective for changing printing behaviors, whereas habit change methods may be more appropriate for switching behaviors.

\section{Conclusion}

This study examined the effect of social-cognitive factors, perceived habit, and organizational contextual factors on energy-saving behaviors among office workers. The findings suggest that the relative importance of cognitive factors and habit varies between office energy-saving behaviors and to a lesser extent between organizations. Organizational contextual effects were only partially mediated by socialcognitive factors and habit for some energysaving behaviors, suggesting that some contextual influences on behavior are unconscious.

Open Access This article is distributed under the terms of the Creative Commons Attribution License which permits any use, distribution, and reproduction in any medium, provided the original author(s) and the source are credited.

\section{References}

Aarts, H., \& Dijksterhuis, A. (2000). The automatic activation of goal-directed behaviour: the case of travel habit. Journal of Environmental Psychology, 20, 75-82.

Ajzen, I. (1991). The theory of planned behavior. Organizational Behavior and Human Decision Processes, 50, 179-211.

Ajzen, I. (2011). The theory of planned behaviour: reactions and reflections. Psychology \& Health, 26, 1113-1127. doi:10. 1080/08870446.2011.613995.

Bamberg, S., \& Moser, G. (2007). Twenty years after Hines, Hungerford, and Tomera: a new meta-analysis of psychosocial determinants of pro-environmental behaviour. Journal of Environmental Psychology, 27, 14-25.

Bamberg, S., Ajzen, I., \& Schmidt, P. (2003). Choice of travel mode in the theory of planned behavior: the roles of past behavior, habit, and reasoned action. Basic and Applied Social Psychology, 25, 175-187.

Bamberg, S., Hunecke, M., \& Blobaum, A. (2007). Social context, personal norms and the use of public transportation: two field studies. Journal of Environmental Psychology, 27, 190-203.

Bansal, P., \& Gao, J. J. (2006). Building the future by looking to the past - examining research published on organizations and environment. Organization \& Environment, 19, 458-478.

Bargh, J. A., \& Morsella, E. (2008). The unconscious mind. Perspectives on Psychological Science, 3, 73-79.

Bartholomew, L. K., Parcel, G. S., Kok, G., Gottlieb, N., \& Fernández, M. E. (2011). Planning health promotion programs: An intervention mapping approach (3rd ed.). San Francisco: Jossey-Bass.

Brothers, K. J., Krantz, P. J., \& McClannahan, L. E. (1994). Office paper recycling - a function of container proximity. Journal of Applied Behavior Analysis, 27, 153-160.

Carrus, G., Passafaro, P., \& Bonnes, M. (2008). Emotions, habits and rational choices in ecological behaviours: the case of recycling and use of public transportation. Journal of Environmental Psychology, 28, 51-62.

de Groot, G. M., \& Morgenstern, P. P. (2009). Energieverbruik en besparingspotentieel bedrijven en instellingen [energy use and saving potential companies and institutions] RIVM [National Institute for Public Health and the Environment].

Dietz, T., Gardner, G. T., Gilligan, J., Stern, P. C., \& Vandenbergh, M. P. (2009). Household actions can provide a behavioral wedge to rapidly reduce US carbon emissions. Proceedings of the National Academy of Sciences of the United States of America, 106, 18452-18456.

Egmond, C., Jonkers, R., \& Kok, G. (2006). A strategy and protocol to increase diffusion of energy related innovations into the mainstream of housing associations. Energy Policy, 34, 4042-4049.

Fishbein, M., \& Ajzen, I. (2010). Predicting and changing behavior: The reasoned action approach. New York: Taylor \& Francis Group.

Harland, P., Staats, H., \& Wilke, H. A. M. (1999). Explaining proenvironmental intention and behavior by personal norms and the theory of planned behavior. Journal of Applied Social Psychology, 29, 2505-2528.

Hassin, R. R., Bargh, J. A., \& Zimerman, S. (2009). Automatic and flexible: the case of nonconscious goal pursuit. Social Cognition, 27, 20-36.

Hu, L. T., \& Bentler, P. M. (1999). Cutoff criteria for fit indexes in covariance structure analysis: conventional criteria versus new alternatives. Structural Equation Modeling, 6, 1-55.

Humphrey, C.-R., Bord, R.-J., Hammond, M.-M., \& Mann, S.-H. (1977). Attitudes and conditions for cooperation in a paper recycling program. Environment and Behavior, 9, 107-124.

Kaiser, F. G. (2006). A moral extension of the theory of planned behavior: norms and anticipated feelings of regret in conservationism. Personality and Individual Differences, $41,71-81$.

Kaiser, F. G., Hubner, G., \& Bogner, F. X. (2005). Contrasting the theory of planned behavior with the value-belief-norm model in explaining conservation behavior. Journal of Applied Social Psychology, 35, 2150-2170.

Knussen, C., Yule, F., MacKenzie, J., \& Wells, M. (2004). An analysis of intentions to recycle household waste: the roles of past behaviour, perceived habit, and perceived lack of facilities. Journal of Environmental Psychology, 24, 237-246.

Kremers, S. P. J. (2010). Theory and practice in the study of influences on energy balance-related behaviors. Patient Education and Counseling, 79, 291-298. doi:10.1016/j.pec.2010.03.002.

Latane, B., Williams, K., \& Harkins, S. (1979). Many hands make light the work - causes and consequences of social loafing. Journal of Personality and Social Psychology, 37, 822-832. doi:10.1037//0022-3514.37.6.822.

Lo, S. H., Peters, G. Y., \& Kok, G. (2012a). Energy-related behaviors in office buildings: a qualitative study on individual and organizational determinants. Applied Psychology: An 
International Review, 61, 227-249. doi:10.1111/j.1464-0597. 2011.00464.x.

Lo, S. H., Peters, G. Y., \& Kok, G. (2012b). A review of determinants of and interventions for proenvironmental behaviors in organizations. Journal of Applied Social Psychology, 42, 2933-2967. doi:10.1111/j.1559-1816.2012.00969.x.

Muthén, L. K., \& Muthén, B. O. (1998-2010). Mplus User's Guide. Sixth Edition. Los Angeles: Muthén \& Muthén.

Ouellette, J. A., \& Wood, W. (1998). Habit and intention in everyday life: the multiple processes by which past behavior predicts future behavior. [Review]. Psychological Bulletin, 124, 54-74. doi:10.1037/0033-2909.124.1.54.

Parker, D., Manstead, A. S. R., \& Stradling, S. G. (1995). Extending the theory of planned behavior - the role of personal norm. British Journal of Social Psychology, 34, 127-137.

Perez-Lombard, L., Ortiz, J., \& Pout, C. (2008). A review on buildings energy consumption information. Energy and Buildings, 40, 394-398.

Satorra, A., \& Bentler, P. M. (1994). Corrections to test statistics and standard enors in covariance structure analysis. In A. von Eye \& C. C. Clogg (Eds.), Latent variables analysis: applications for developmental research (pp. 399-419). Thousand Oaks: Sage.

Satorra, A., \& Bentler, P. M. (2001). A scaled difference chisquare test statistic for moment structure analysis. Psychometrika, 66, 507-514.
Schultz, P. W., Nolan, J. M., Cialdini, R. B., Goldstein, N. J., \& Griskevicius, V. (2007). The constructive, destructive and reconstructive power of social norms. Psychological Science, 18, 429-434.

Siero, S., Boon, M. E., Kok, G. J., Siero, F. W., \& Veen, P. (1984). Implementatie van energiebesparend gedrag in een grote organisatie. $M \& O$, Tijdschrift voor Organisatiekunde en Sociaal Beleid, 38, 323-338.

Thogersen, J. (2006). Understanding repetitive travel mode choices in a stable context: a panel study approach. Transportation Research Part a-Policy and Practice, 40, 621-638.

Vermeulen, W. J. V., \& Hovens, J. (2006). Competing explanations for adopting energy innovations for new office buildings. Energy Policy, 34, 2719-2735.

Verplanken, B., \& Orbell, S. (2003). Reflections on past behavior: a self-report index of habit strength. Journal of Applied Social Psychology, 33, 1313-1330.

Völlink, T., Meertens, R., \& Midden, C. J. H. (2002). Innovating 'diffusion of innovation' theory: innovation characteristics and the intention of utility companies to adopt energy conservation interventions. Journal of Environmental Psychology, 22(4), 333-344.

Wood, W., Tam, L., \& Guerrero Witt, M. (2005). Changing circumstances, disrupting habits. Journal of Personality and Social Psychology, 88, 918-933. 